\title{
The Use of Gardening and Green Space Therapy in Mental Health is Increasingly Important
}

\author{
Richard Thompson*
}

36, Dealtry Road, London, SW15 6NL, UK

Article Info

\section{Article Notes}

Received: December 21, 2018

Accepted: January 30, 2019

\section{*Correspondence:}

Dr. Richard Thompson, 36, Dealtry Road, London, SW15 6NL, UK; Email: richard@rpht.co.uk.

(C) 2019 Thompson R. This article is distributed under the terms of the Creative Commons Attribution 4.0 International License.

\section{Keywords}

Gardening

Green space

Social prescribing

Indoor plants

Care farms

Post traumatic stress disorder

Dementia

\section{Abstract}

Exposure to green plants, green space and gardening is now recognised as a valuable type of social prescribing for problems of mental and physical health, and the evidence behind their beneficial effects is strong.

In many countries, including the United Kingdom (UK), Health Services are under increasing pressure of workload and since this will inexorably continue, even with appropriately increased funding, every attempt to improve the health of the population and prevent illness must be welcomed. Thus gardening and green care, which are forms of complementary therapy and social prescribing, are cheap, safe and effective treatments for mental and physical problems, and can help to improve the disparity between the efficacy of treatments for physical and mental health ${ }^{1,2,3}$. Such alternatives to increasingly expensive drug therapies must be studied and applied, if only to reduce the incidence of the increasingly complex side effects of drugs, and the large number of admissions to hospital and deaths that are attributed to these.

Gardens were promoted by Florence Nightingale and the early Mayo Clinic, and have been an important part of many psychiatric and general hospitals. Recent research has now clearly shown that simple exposure to plants, visiting green spaces, and gardening itself can all be beneficial to mental and physical health ${ }^{4,5}$. Perhaps the most quoted studies are those of the environmental psychologist Roger Ulrich who, working in the USA and Sweden, convincingly showed in randomised trials that, for instance, a green view of trees from post operative hospital wards significantly reduced patients' pain and length of stay, and that even being shown large pictures of the countryside in the ward was effective. Presumably these effects were psychological, positively affecting the attitude of patients towards pain and recovery. Of the many paintings on the walls of a Swedish psychiatric hospital that were vandalised by patients, all were of abstract subjects and none was of a natural scene; so perhaps art galleries are not always good for health? Gardens in prisons can benefit physical and mental health ${ }^{6}$; in a prison in Michigan prisoners with a view over countryside through the bars of their cells used the medical services less than those whose only view was of a courtyard.

In several countries, associations have been demonstrated between the proximity to trees and green space and lower levels of depression, anxiety and stress, and green space seems also to 
reduce the health inequalities associated with deprivation ${ }^{2}$. Interestingly, the social interaction that comes with green space may be more important than the physical activity of walking, although it also could be partly due to the improved air quality and reduced airborne pollution in the area. Hospital gardens reduce stress, both for the patients and staff, and the recent roll-out of inspiring gardens in spinal units in the UK, in memory of Horatio Chapple and supported by the National Garden Scheme (NGS), are proving strikingly popular for mentally traumatised and disabled patients in wheelchairs and beds who can now access these spaces, and for the staff and visitors to the units ${ }^{2}$. The NGS is also supporting the development of gardens around cancer centers, hospices and care homes.

Mind, the mental health charity in England and Wales, compared the effects of short walks through a garden compared to being in a shopping complex, and found rapidly improved parameters of mental health ${ }^{7}$ ! Even growing plants in rooms is beneficial to mental health, perhaps because of the removal by the leaves of toxins, microorganisms and dust from the air, as do trees and plants outside, including turf.

Gardening itself is therapeutic, and not just to physical health, for it has been associated with a positive effect on health in several countries and a reduction of the cost of mental health services. For some years spells within Green Care Farms in Northern Europe have been successfully prescribed for patients with mental health problems, learning disabilities and drug dependency. In England, National Care Farms have similarly been set up by the University of Essex, and the positive effects on the more than 3000 patients who attend each week have been independently assessed. The physical benefits of the exercise associated with gardening are easy to understand and well studied, but it may also be the sunlight and social interaction that underlie the benefits to mental health. For instance, patients with learning disabilities are often isolated, and their visits to a therapeutic garden, of which there are 800 in England and Wales according the charity Thrive, which enables therapeutic gardening in the UK, can be life changing. There is also evidence that gardening delays dementia; thus an Australian study showed that gardening is more effective than walking, education or moderate alcohol intake in preventing the onset of dementia. Military veterans with post traumatic stress disorder are greatly benefitted by gardening ${ }^{8}$.

No wonder that the UK Health Secretary, Public Health England and the Department of Health have lighted upon gardening and green space as agents to improve mental and physical health, and thus prevent the need for drug therapy or admission to hospital; they should be incorporated into the Public Health England programmes for improving public health. They could improve drug dependency. Gardening and time spent in green space should be considered to be one type of alternative therapy, as are equine therapy, music, knitting, or group therapy. So many patients with mental health problems could be encouraged to take up or continue with gardening and increase their exposure to green space. The effects are less intuitive than for physical health, but the benefits are no less real or well researched.

For their part, health professionals should also be active in pressing for more green spaces, trees, therapeutic gardens and allotments in the urban environment, and for more gardening to be taught in schools.

\section{Conflicts of Interest}

Past- president of the Royal College of Physicians, London, Trustee of the National Garden Scheme, and a Patron of the therapeutic gardening charity Thrive.

\section{References}

1. Buck D. Gardens and health; implications for policy and practice. 2016. King's Fund.

2. Thompson R. Gardening for health: a regular dose of gardening. Clinical Medicine. 2018; 18: 201-205.

3. Sempik J, Aldridge J, Becker S. Social and therapeutic horticulture: evidence and messages from research. Loughborough Centre for Child and Family Research, Loughborough University. 2003.

4. Ulrich RS. View through a window may influence recovery from surgery. Science. 1984; 224: 420-421.

5. Ulrich RS. Health benefits of gardens in hospitals. Plants for People Conference. 2002.

6. Wright H. Outside time. Placewise. 2017.

7. Peacock J, Hine R, Pretty J. The mental health benefits of green exercise activities and green care. Report for MIND. 2007.

8. Wise J. Digging for victory. Horticultural therapy with veterans for post-traumatic growth. Karnac Books.2015. 